\title{
Effects of the Mn/Fe Ratio and Cooling Rate on the Modification of Fe Intermetallic Compounds in Cast A356 Based Alloy with Different Fe Contents
}

\author{
Zhijun Zhang ${ }^{1, * 1}$, Hiroyasu Tezuka ${ }^{1}$, Equo Kobayashi ${ }^{1, * 2}$ and Tatsuo Sato ${ }^{2}$ \\ ${ }^{1}$ Department of Metallurgy and Ceramics Science, Tokyo Institute of Technology, Tokyo 152-8552, Japan \\ ${ }^{2}$ Precision and Intelligence Laboratory, Tokyo Institute of Technology, Yokohama 226-8503, Japan
}

In cast Al-Si alloys, the platelet $\beta$ type Fe intermetallic compound has been considered as most detrimental Fe compounds to their mechanical properties, especially ductility. When the Fe is inevitable, to enhance the properties of the cast aluminum alloys, the modification of Fe compounds from the platelet $\beta$ type Fe compound to a more compact and less harmful $\alpha$ type Fe compound having the Chinese script morphology becomes the efficient and important way. This work mainly investigated how did three factors, Fe content, Mn/Fe ratio and cooling rate combined influence this modification process in cast A356 (JIS, AC4C) based alloys. The results revealed that with increasing the Fe content in the alloy without $\mathrm{Mn}$ addition, the size of the platelet $\beta$ type Fe compound increases significantly under the same cooling rate. The Mn addition was effective to modify the platelet $\beta$ type Fe compound to more compact Chinese script and/or polyhedral shape $\alpha$ type Fe compound. The ratio of these two kinds of $\alpha$ type Fe compounds mainly depends on the $\mathrm{Mn} / \mathrm{Fe}$ ratio and the cooling rate in a given Fe level. The further research work about the solidification sequence of Fe compounds during casting revealed that in the alloys without Mn addition, the Fe compounds only appeared as a platelet shape. With Mn addition, the Fe compound crystallized as the platelet $\beta$ type compound at the beginning of the solidification. With the solidification proceeding, the Chinese script $\alpha$ type Fe compound became the dominant one. The formation of the polyhedral shape $\alpha$ type Fe compound mainly came from the growth of the Chinese script $\alpha$ type Fe compound. The ratio of these three Fe compounds was greatly influenced by the Mn/Fe ratio and cooling rate in a given Fe content. [doi:10.2320/matertrans.F-M2013808]

(Received November 20, 2012; Accepted May 8, 2013; Published June 21, 2013)

Keywords: cast aluminum alloys, iron intermetallic compounds, modification, solidification sequence

\section{Introduction}

Fe is always present in aluminum as a dominant impurity. Iron comes into aluminum from ores, anodic mass, master alloys, as well as from the steel equipment used in melting and casting. ${ }^{1)}$ Especially in the recycled alloys, the $\mathrm{Fe}$ concentration usually is very high. In cast Al-Si alloys, it is widely accepted that $\mathrm{Fe}$ is the most detrimental impurity. Three main kinds of brittle $\mathrm{Fe}$ intermetallic compounds can be formed by reacting of $\mathrm{Fe}$ with $\mathrm{Al}$ and $\mathrm{Si}$ during solidification process due to its small solid solubility in the Al matrix. ${ }^{2}$ The Fe intermetallic compounds are assumed to act as stress raisers and are points of weak bond, causing reduction in mechanical properties, particularly the ductility of cast alloys. The deterioration of mechanical properties depends on the amount, size and type of Fe compounds. Among the three main Fe-rich compounds in cast $\mathrm{Al}-\mathrm{Si}$ alloys, $\beta$ type Fe compound which usually appears as the platelet shape (needle-like in the 2-D cross-section image), has been identified as the most detrimental one in Al-Si alloy castings. ${ }^{3-5)}$ The solubility of $\mathrm{Mn}$ in the $\beta$ type $\mathrm{Fe}$ compound is very small. In the presence of more $\mathrm{Mn}$ addition, the chemical formula for another common $\mathrm{Fe}$ compound formed can be represented approximately by $\mathrm{Al}_{15}(\mathrm{Fe}, \mathrm{Mn})_{3} \mathrm{Si}_{2}$, known as $\alpha$ type Fe compound having an appearance of the Chinese script morphology in section. ${ }^{6,7)}$ If $\mathrm{Fe}$ and $\mathrm{Mn}$ are sufficiently high, the third kind of $\mathrm{Fe}$ compound, which has the similar composition and crystal structure as that of the Chinese script $\alpha$ type Fe compound, also confusingly known as the $\alpha$ type $\mathrm{Fe}$ compound but

\footnotetext{
${ }^{* 1}$ Graduate Student, Tokyo Institute of Technology

${ }^{* 2}$ Corresponding author, E-mail: equo@mtl.titech.ac.jp
}

with the polyhedral shape. ${ }^{8,9)}$ This compound has been thought not to embrittle the alloy, but reduce the machinability and its formation should be avoided. ${ }^{6)}$ Efforts are made to keep the $\mathrm{Fe}$ contents in $\mathrm{Al}$ alloys as low as possible. The strict requirement for low levels of $\mathrm{Fe}$ in the cast aluminum alloys significantly increases costs. Hence, how to improve the mechanical properties of cast aluminum alloys with high $\mathrm{Fe}$ content becomes important and necessary. When the $\mathrm{Fe}$ compounds are inevitable, the Chinese script $\alpha$ type Fe compound or the small size $\mathrm{Fe}$ compounds are preferable. ${ }^{10)}$

Mn was usually added into the alloy to modify the platelet $\beta$ type $\mathrm{Fe}$ compound to the Chinese script $\alpha$ type $\mathrm{Fe}$ compound. ${ }^{11)}$ Although the addition of Mn to Al-Si alloys has been widely investigated and documented, the amount of $\mathrm{Mn}$ needed to neutralize $\mathrm{Fe}$ has not been well established, especially with the change in the cooling rate. ${ }^{12,13)}$ The previous works mainly revealed the influences of the $\mathrm{Mn}$ and $\mathrm{Fe}$ content on the type and size of different $\mathrm{Fe}$ compounds $^{14-16)}$ or the cooling rate on the evolution of different Fe compounds during the modification process ${ }^{17,18)}$ separately. Still very limited work has reported systematically about the influences of the Fe content, the $\mathrm{Fe} / \mathrm{Mn}$ ratio and cooling rate on the modification of Fe compounds. This work mainly investigate the combined influences of the $\mathrm{Mn} / \mathrm{Fe}$ ratio and cooling rate on the modification of $\mathrm{Fe}$ compounds in cast A356 (JIS, AC4C) based alloys with different Fe contents. Moreover, in order to control this modification process well, to know the detailed solidification sequence of the different $\mathrm{Fe}$ compounds are essential. In this work, the water-quenched experiments were conducted to reveal the solidification sequence of the different Fe intermetallic compounds. 
Table 1 Nominal compositions of the A356 based alloys with different Fe and $\mathrm{Mn}$ contents. The $\mathrm{Mn} / \mathrm{Fe}$ ratios in each set are $0,0.35,0.5$ and 0.65 respectively. The samples are named as $x \mathrm{Fe}$ or $x \mathrm{Fe}+y$ in the text, where the $x$ represents the $\mathrm{Fe}$ content (in mass\%) and $y$ represents the $\mathrm{Mn} / \mathrm{Fe}$ ratio.

\begin{tabular}{cccccc}
\hline \multirow{2}{*}{ Alloys } & \multicolumn{5}{c}{ Elements (mass\%) } \\
\cline { 2 - 6 } & Al & Si & Mg & Fe & Mn \\
\hline Set 1 & Bal. & 7.00 & 0.35 & 1.0 & $0,0.35,0.5,0.65$ \\
Set 2 & Bal. & 7.00 & 0.35 & 1.5 & $0,0.525,0.75,0.975$ \\
Set 3 & Bal. & 7.00 & 0.35 & 2.0 & $0,0.7,1.0,1.3$ \\
Set 4 & Bal. & 7.00 & 0.35 & 2.5 & $0,0.875,1.25,1.625$ \\
\hline
\end{tabular}

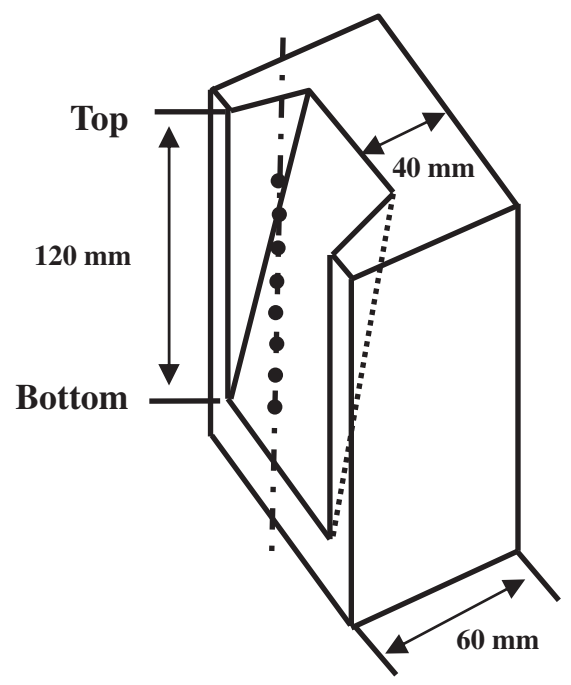

Fig. 1 Schematic drawing of a half of the symmetrical stainless steel casting mold for the wedge-shaped samples. The locations of the thermocouples during casting were marked by the close rounds. They are $20,30,40,50,60,70,80$ and $90 \mathrm{~mm}$ from the bottom of the mold.

\section{Experimental Procedure}

The alloys were molten in a graphite crucible under an Ar protective atmosphere by an electrical resistance furnace. The nominal compositions of the experimental A356 based alloys are given in Table 1 . The Fe contents in each alloy are 1.0, 1.5, 2.0 and 2.5 mass\%, respectively. Different $\mathrm{Mn}$ contents were added to make sure the $\mathrm{Mn} / \mathrm{Fe}$ ratio are 0 , $0.35,0.5$ and 0.65 , respectively. The samples are named as $x$ $\mathrm{Fe}$ or $x \mathrm{Fe}+y$ in the text, where the $x$ represents the $\mathrm{Fe}$ content (in mass \%) and $y$ represents the $\mathrm{Mn} / \mathrm{Fe}$ ratio. Each alloy was cast into a stainless steel mold, as shown in Fig. 1. The thickness of the mold walls was designed getting thinner gradually from the bottom $(60 \mathrm{~mm})$ to the top $(40 \mathrm{~mm})$ to get the wedge shape cast. Hence, the different heights of the cast show the different cooling rates. During casting, the thermocouples were set in the center of the mold at different heights $(20,30,40,50,60,70,80$ and $90 \mathrm{~mm}$ from the bottom of the mold), to monitor the cooling curves. The calculated cooling rates based on the cooling curves were showed in Fig. 2. The casting temperature of $993 \mathrm{~K}$ was used throughout this study.

To investigate the solidification sequence of the different $\mathrm{Fe}$ compounds, the water-quenched experiments during air

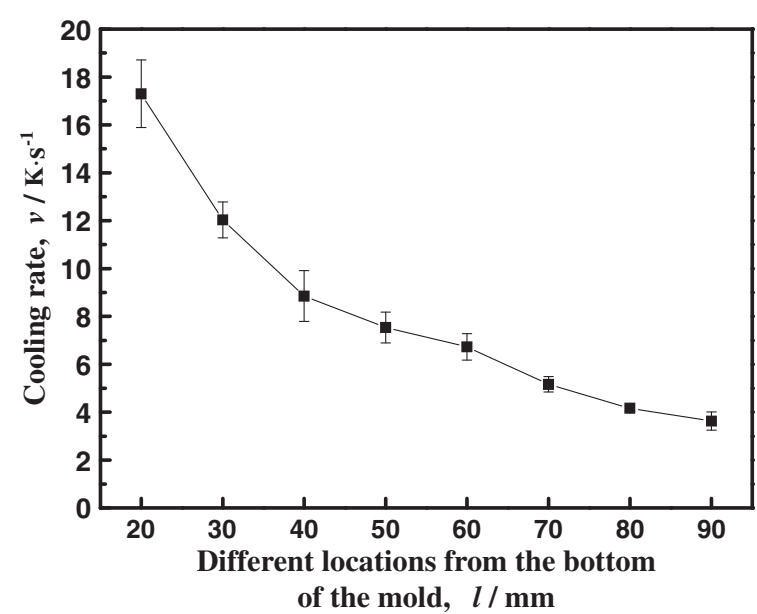

Fig. 2 Values of the cooling rates are averaged for the alloys with different $\mathrm{Fe}$ contents and no Mn addition.

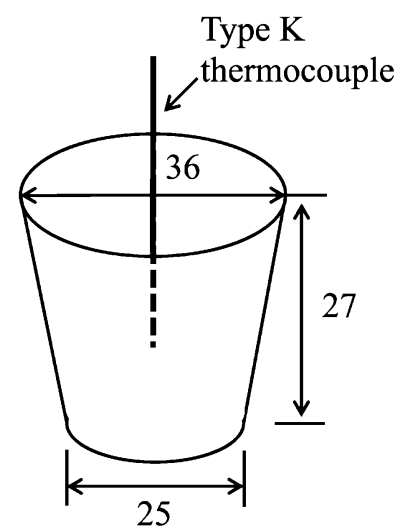

Fig. 3 Schematic drawing of the stainless steel cup for water-quenched experiment $(\mathrm{mm})$.

cooling were performed. The stainless steel cups coated with a thin layer of boron nitride were used, as shown in Fig. 3. The cup was filled by dipping into the melt, temporarily immersing it to attain thermal equilibrium with the melt. The mold with its liquid metal was then removed from the melt and solidified in air. The K-type thermocouples were located in the central areas of the cups to monitor the cooling curves during air cooling just after taking out the cups from the molten alloys. The cooling rate of this cup mold during air cooling is $0.59 \mathrm{~K} / \mathrm{s}$. The onset of the air cooling was counted from the time taking out the cups from the melt. For each alloy composition, four interrupted water-quenched experiments were carried out at 5,20,50 and $180 \mathrm{~s}$ timing from the start of the air cooling. The air cooling time which was used in the following description represents the period between onset of the air cooling and the water-quenched time.

The modification of $\mathrm{Fe}$ compounds was mainly revealed by the morphology change of the shape and size of the different $\mathrm{Fe}$ compounds. Optical microscope was used to characterize the microstructure. Samples for the microstructural analysis were prepared by standard techniques with the final polishing stage using the $0.05 \mu \mathrm{m}$ colloidal silica. 


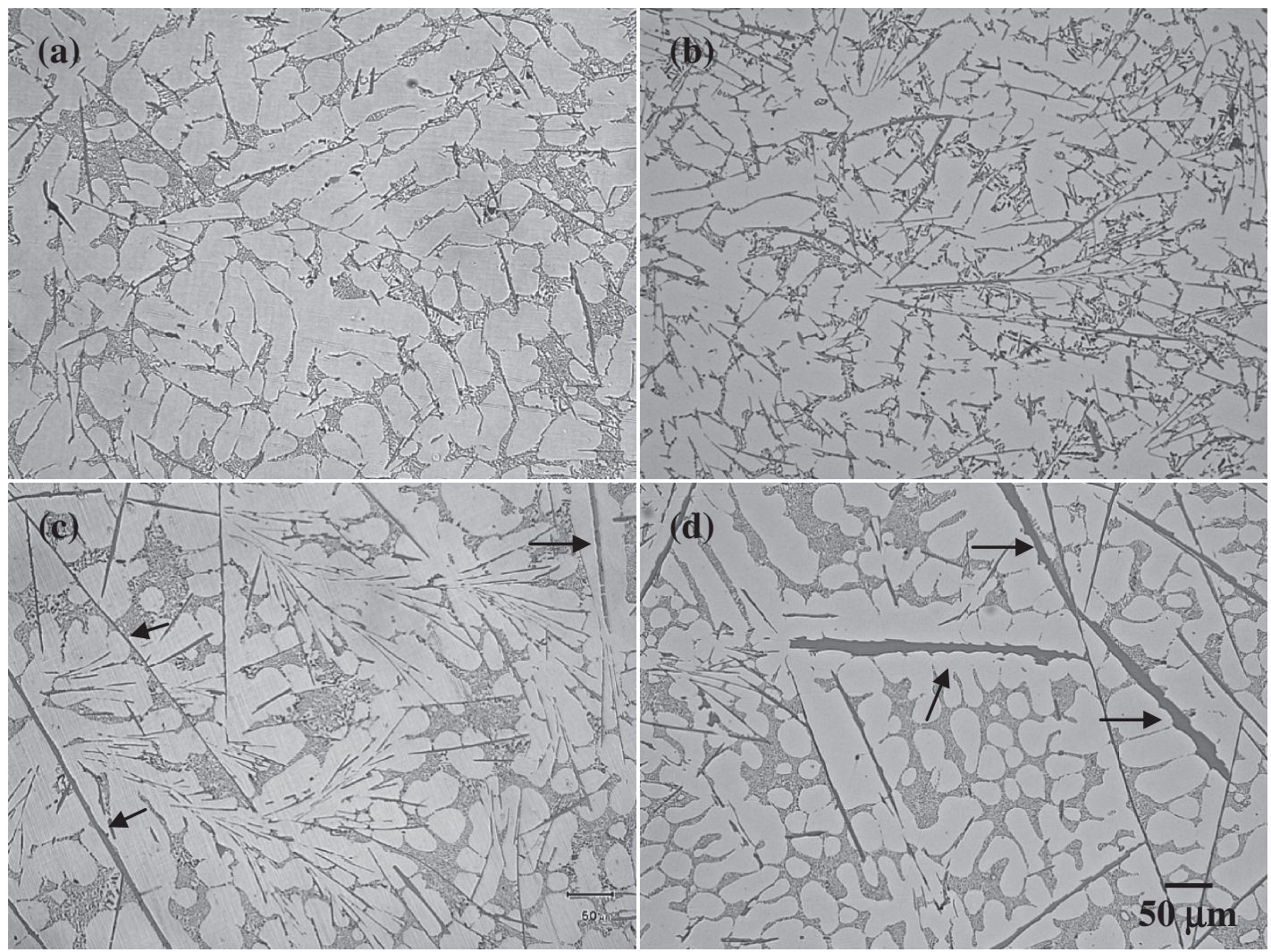

Fig. 4 Microstructures of the alloys with different Fe contents at the height of $90 \mathrm{~mm}$ from the bottom of the mold: (a) 1.0 Fe, (b) $1.5 \mathrm{Fe}$,

(c) $2.0 \mathrm{Fe}$, (d) $2.5 \mathrm{Fe}$. The large size platelet $\beta$ type Fe compound particles are indicated by the arrows.

\section{Results}

\subsection{Effect of the Fe content}

Microstructures of the alloys with different Fe contents at the low cooling rate $(3.6 \mathrm{~K} / \mathrm{s}, 90 \mathrm{~mm})$ were showed in Fig. 4. The size of the platelet $\beta$ type $\mathrm{Fe}$ compound particles significantly increases with increasing the Fe content. The larger size platelet $\beta$ type $\mathrm{Fe}$ compound particles marked by the arrows in Figs. 4(c) and 4(d) demonstrated that with increasing the $\mathrm{Fe}$ content, the $\beta$ type $\mathrm{Fe}$ compound crystallized at higher temperature. Longer growth time will make the size of the $\beta$ type compound much larger.

\subsection{Effect of the Mn/Fe ratio}

The addition of $\mathrm{Mn}$ modified the platelet $\beta$ type $\mathrm{Fe}$ compound to $\alpha$ type Fe compound which appeared as both Chinese script and polyhedral shape, as shown in Fig. 5. In the alloy with both low Fe content and low $\mathrm{Mn} / \mathrm{Fe}$ ratio, the alloy $1.0 \mathrm{Fe}+0.35$, almost all of the $\mathrm{Fe}$ compound particles showed the platelet shape, as shown in Fig. 5(a). With increasing the $\mathrm{Mn} / \mathrm{Fe}$ ratio, some of the platelet shape $\beta$ type Fe compound particles were modified to the Chinese script $\alpha$ type Fe compound particles, marked by arrows in Fig. 5(b). When the $\mathrm{Mn} / \mathrm{Fe}$ ratio reached up to 0.65 , most of the platelet $\beta$ type $\mathrm{Fe}$ compound particles were modified. However, still some platelet $\beta$ type Fe compound particles existed, as shown in Fig. 5(c) marked by arrows.

By increasing the Fe content from 1.0 to 2.0 mass $\%$ with the $\mathrm{Mn} / \mathrm{Fe}$ ratio of 0.35 , some of the platelet $\beta$ type $\mathrm{Fe}$ compound particles were modified to both the Chinese script and polyhedral shape $\alpha$ type Fe compound particles, as shown in Fig. 5(d). With increasing the $\mathrm{Mn} / \mathrm{Fe}$ ratio to 0.5 , almost all the platelet $\beta$ type Fe compound particles were replaced by $\alpha$ type Fe compound particles. The ratio of the polyhedral shape $\alpha$ type Fe compound particles greatly increased, as shown in Fig. 5(e). When the $\mathrm{Mn} / \mathrm{Fe}$ ratio was increased to 0.65 , most of the Fe compounds became as the polyhedral shape, as shown in Fig. 5(f).

When the Fe content was 2.5 mass \%, the modification of the Fe compounds by Mn addition showed the similar phenomenon as that of the alloys with 2.0 mass $\% \mathrm{Fe}$ and different $\mathrm{Mn} / \mathrm{Fe}$ ratio, as shown in Figs. 5(g)-5(i). The difference is that at the same $\mathrm{Mn} / \mathrm{Fe}$ ratio, the volume fraction of the polyhedral shape $\alpha$ type $\mathrm{Fe}$ compound particles increased, as shown in Figs. 5(f) and 5(i).

\subsection{Effect of the cooling rate}

Figure 6 shows the microstructures of the alloys $1.0 \mathrm{Fe}$ and $2.5 \mathrm{Fe}$ at different cooling rates. In the alloy without the Mn addition, all the Fe compounds appeared in the form of platelet shape, as shown in Fig. 6. Changing the cooling rate can not modify the Fe compound in the type. However, the size of the Fe compounds can be altered. With increasing the cooling rate from $3.6 \mathrm{~K} / \mathrm{s}(90 \mathrm{~mm})$ to $17.3 \mathrm{~K} / \mathrm{s}(20 \mathrm{~mm})$, the size of the $\beta$ type Fe compound particles was refined from the large one to the small one, regardless of the Fe content.

In the alloy $1.0 \mathrm{Fe}+0.65$ at the low cooling rate $(3.6 \mathrm{~K} / \mathrm{s}$, $90 \mathrm{~mm}$ ), most of the $\mathrm{Fe}$ compounds showed the Chinese script morphology, as shown in Fig. 7(a). With increasing the cooling rate, $\mathrm{Fe}$ compounds tended to appear in the form of 


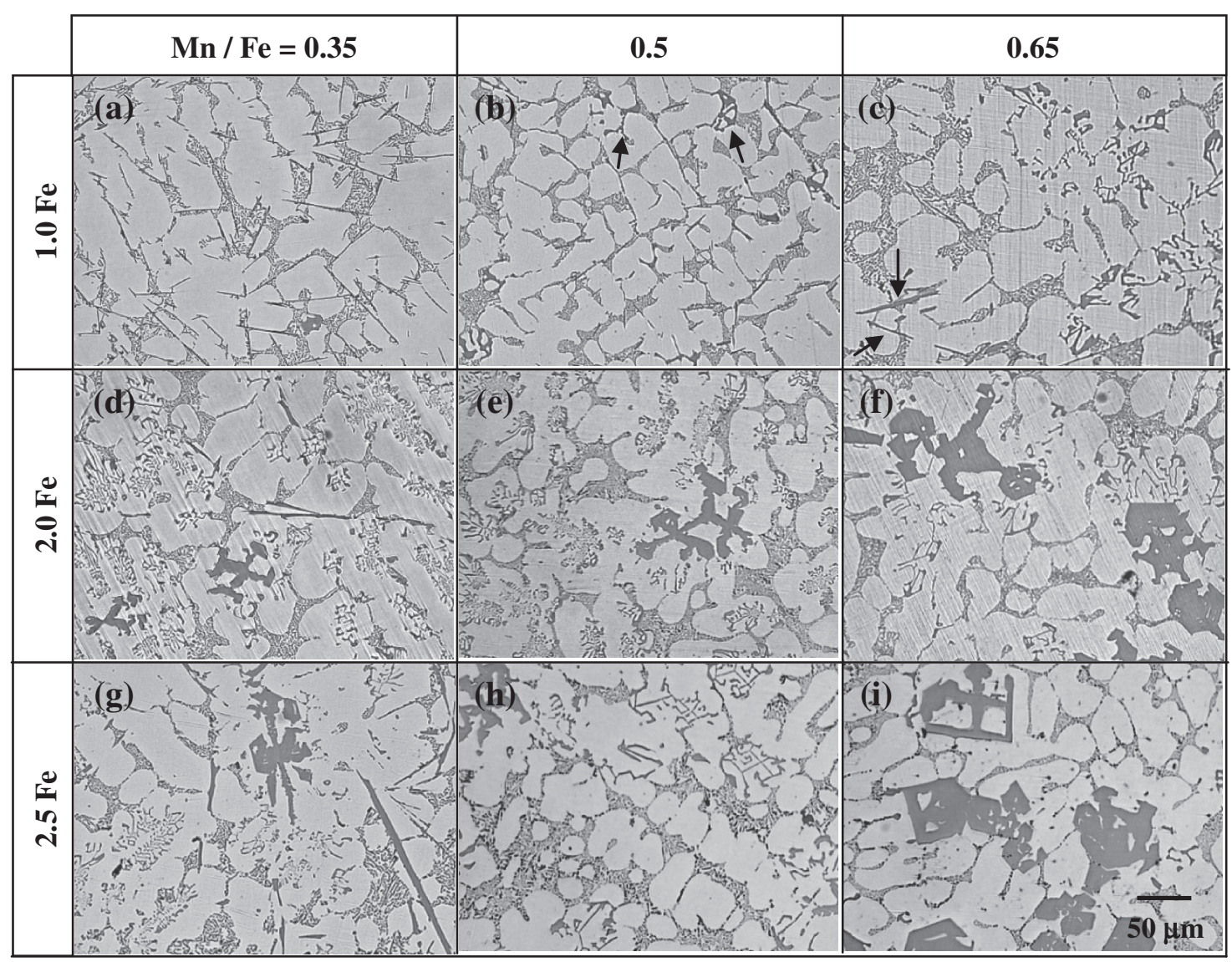

Fig. 5 Microstructures of the alloys with different $\mathrm{Fe}$ contents and $\mathrm{Mn} / \mathrm{Fe}$ ratios at the height of $90 \mathrm{~mm}$ from the bottom of the mold: (a) $1.0 \mathrm{Fe}+0.35$ (b) $1.0 \mathrm{Fe}+0.5$ (c) $1.0 \mathrm{Fe}+0.65$ (d) $2.0 \mathrm{Fe}+0.35$ (e) $2.0 \mathrm{Fe}+0.5$ (f) $2.0 \mathrm{Fe}+0.65$ (g) $2.5 \mathrm{Fe}+0.35$ (h) 2.5 $\mathrm{Fe}+0.5$ (i) $2.5 \mathrm{Fe}+0.65$.

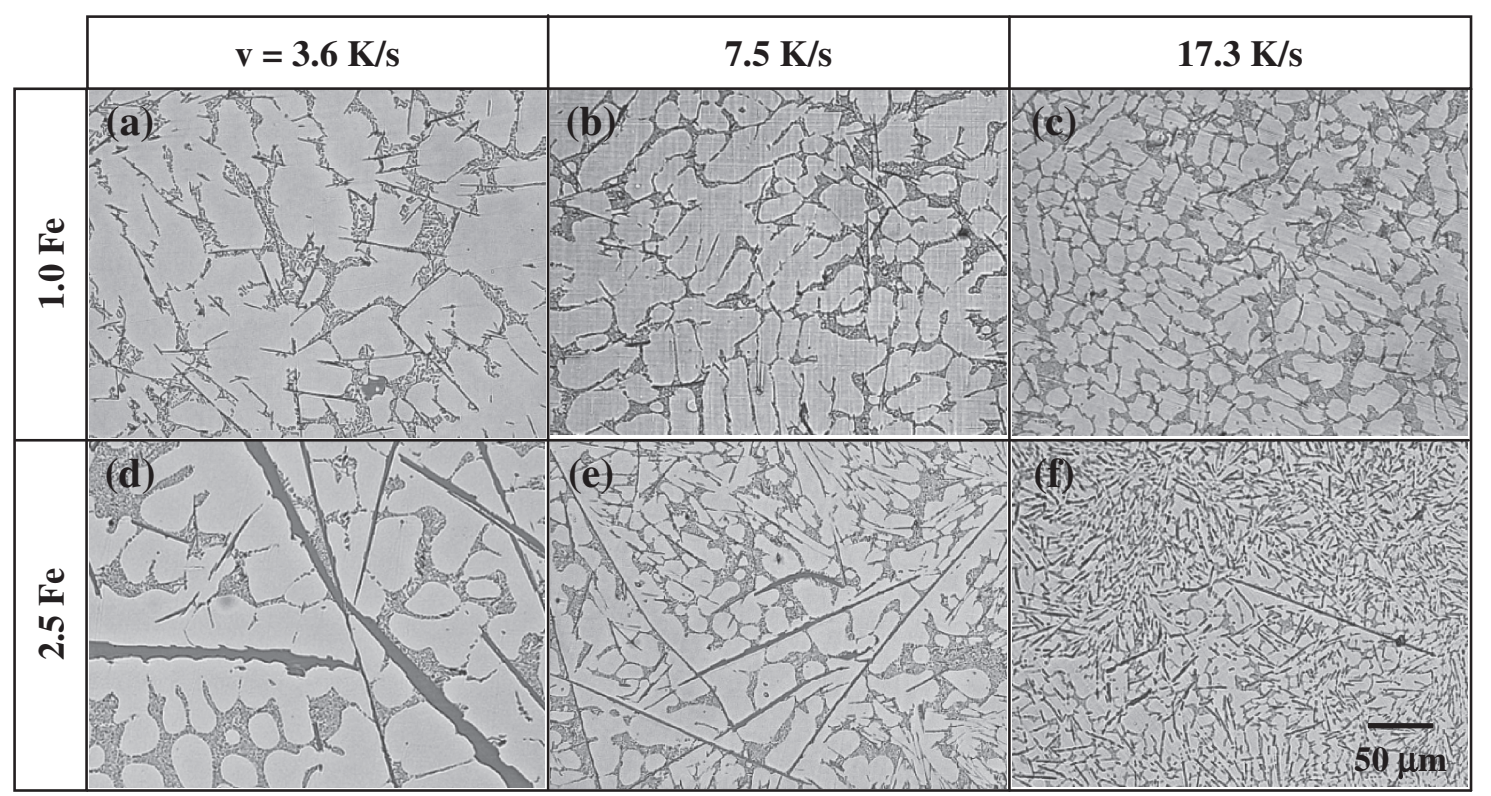

Fig. 6 Microstructures of the alloys at different heights from the bottom of the mold, 1.0 Fe: (a) $90 \mathrm{~mm}, 3.6 \mathrm{~K} / \mathrm{s}$ (b) $50 \mathrm{~mm}, 7.5 \mathrm{~K} / \mathrm{s}$ (c) $20 \mathrm{~mm}, 17.3 \mathrm{~K} / \mathrm{s} ; 2.5 \mathrm{Fe}$ : (d) $90 \mathrm{~mm}, 3.6 \mathrm{~K} / \mathrm{s}$ (e) $50 \mathrm{~mm}, 7.5 \mathrm{~K} / \mathrm{s}$ (f) $20 \mathrm{~mm}, 17.3 \mathrm{~K} / \mathrm{s}$.

the platelet shape, as shown in Fig. 7(b). At high cooling rate $(17.3 \mathrm{~K} / \mathrm{s}, 20 \mathrm{~mm})$, most of the Fe compounds appeared in the form of the small platelet shape, as shown in Fig. 7(c). In the alloy $2.5 \mathrm{Fe}+0.65$ at low cooling rate $(3.6 \mathrm{~K} / \mathrm{s}, 90 \mathrm{~mm})$, most of the $\mathrm{Fe}$ compounds appeared in the form of the polyhedral shape, as shown in Fig. 7(d). With increasing the cooling rate, the size of $\mathrm{Fe}$ compounds decreased. Also, the Chinese script $\alpha$ type Fe compound is preferentially formed, 


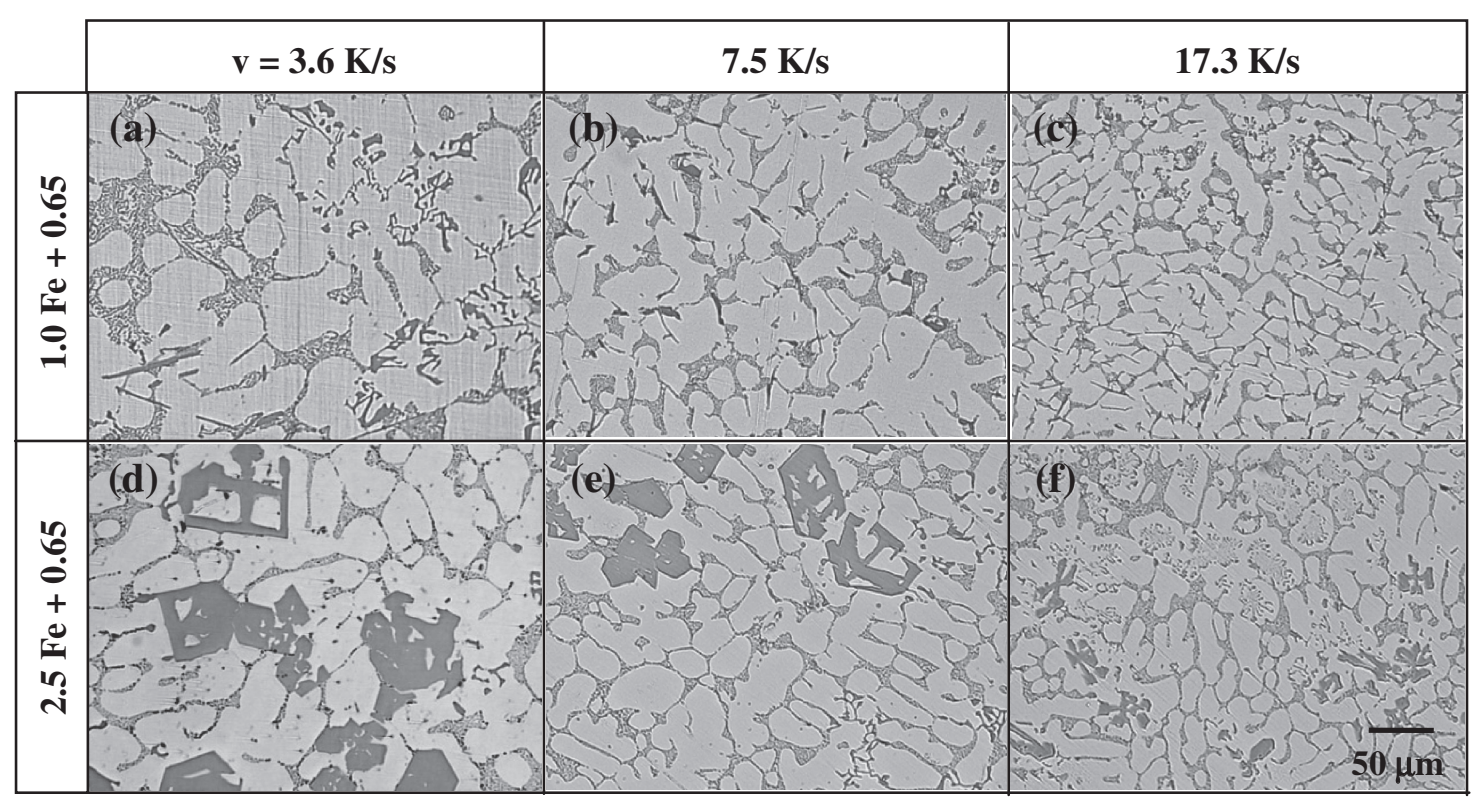

Fig. 7 Microstructures of the alloys at different heights from the bottom of the mold, $1.0 \mathrm{Fe}+0.65:$ (a) $90 \mathrm{~mm}$, $3.6 \mathrm{~K} / \mathrm{s}$ (b) $50 \mathrm{~mm}$,

$7.5 \mathrm{~K} / \mathrm{s}$ (c) $20 \mathrm{~mm}, 17.3 \mathrm{~K} / \mathrm{s} ; 2.5 \mathrm{Fe}+0.65:$ (d) $90 \mathrm{~mm}, 3.6 \mathrm{~K} / \mathrm{s}$ (e) $50 \mathrm{~mm}, 7.5 \mathrm{~K} / \mathrm{s}$ (f) $20 \mathrm{~mm}, 17.3 \mathrm{~K} / \mathrm{s}$.

comparing with the formation of polyhedral shape $\mathrm{Fe}$ compound, as shown in Fig. 7(e). At the high cooling rate $(17.3 \mathrm{~K} / \mathrm{s}, 20 \mathrm{~mm})$, most of the Fe compounds appeared in the shape of Chinese script, as shown in Fig. 7(f). It is found that the high cooling rate suppresses the formation of the polyhedral shape $\mathrm{Fe}$ compounds comparing to the Chinese script.

It is indicted that the high cooling rate favored the formation of the platelet $\beta$ type Fe compound. The high cooling rate, however, restricted the formation of the polyhedral shape Fe compound in the alloy with the high $\mathrm{Fe}$ content and $\mathrm{Mn} / \mathrm{Fe}$ ratio.

\section{Discussions}

The platelet $\beta$ type $\mathrm{Fe}$ compound is known as very detrimental to the mechanical properties of the cast $\mathrm{Al}-\mathrm{Si}$ alloys, especially ductility. The high Fe content tends to cause the larger size platelet $\beta$ type $\mathrm{Fe}$ compound rather than increasing its number density, as shown in Fig. 4. This larger size platelet $\beta$ type Fe compound, which is believed to be more detrimental, is considered to be formed earlier and hence more unconstrained growth occurs. The Fe content is the main factor that influences the morphology of the Fe compounds in cast $\mathrm{Al}-\mathrm{Si}$ alloys. Increasing the cooling rate can restrict the growth of the larger size Fe compounds and other phases, which can be beneficial to the mechanical properties of the cast $\mathrm{Al}$ alloys.

The addition of Mn results in the modification of the morphology and type of intermetallic compounds from the platelet $\beta$ type $\mathrm{Fe}$ compound to the Chinese script and/or polyhedral shape $\alpha$ type Fe compounds. Couture revealed that if the iron content exceeded 0.45 mass $\%$, the Mn content should not be less than the half of the Fe content to modify all of the platelet $\beta$ type $\mathrm{Fe}$ compounds. ${ }^{13)}$ However, in this work, this ratio was greatly affected by both the Fe content and cooling rate.
At the low $\mathrm{Fe}$ content, the high $\mathrm{Mn} / \mathrm{Fe}$ ratio and low cooling rate favor the formation of the Chinese script $\alpha$ type Fe compound, as shown in Fig. 7(a). Decreasing the Mn/Fe ratio and increasing the cooling rate result in the increase in the ratio of the platelet $\beta$ type Fe compound among the Fe compounds, as shown in Figs. 5(a)-5(c) and Figs. 7(b), 7(c). On the other hand, at the high Fe content, the high $\mathrm{Mn} / \mathrm{Fe}$ ratio and low cooling rate favor the formation of the polyhedral shape $\alpha$ type Fe compound, as shown in Fig. 7(d). Decreasing the $\mathrm{Mn} / \mathrm{Fe}$ ratio and increasing the cooling rate result in the decreased ratio of the polyhedral shape $\alpha$ type Fe compound and the increased ratio of the Chinese script $\alpha$ type Fe compound, as shown in Figs. 5(d)-5(i) and Figs. 7(e) and 7(f).

Therefore, in order to modify the platelet $\beta$ type $\mathrm{Fe}$ compound to the Chinese script $\alpha$ type Fe compound and to avoid the formation of the polyhedral shape $\alpha$ type $\mathrm{Fe}$ compound, the critical $\mathrm{Mn} / \mathrm{Fe}$ ratio and cooling rate should be mainly considered at a given Fe content. In the alloy with 1.0 mass $\% \mathrm{Fe}$, the $\mathrm{Mn} / \mathrm{Fe}$ ratio should be larger than 0.65 to modify the remained platelet $\beta$ type $\mathrm{Fe}$ compound at the cooling rate of $3.6 \mathrm{~K} / \mathrm{s}(90 \mathrm{~mm})$, as shown in Fig. 7(a). If increasing the cooling rate under the same situation, this $\mathrm{Mn} / \mathrm{Fe}$ ratio should be much larger, as shown in Figs. 7(b) and 7 (c). In the alloys with 2.0 mass $\% \mathrm{Fe}$ and 2.5 mass $\% \mathrm{Fe}$, the $\mathrm{Mn} / \mathrm{Fe}$ ratio should be between 0.35 and 0.5 to modify the remained platelet $\beta$ type Fe compound and decrease the ratio of the polyhedral shape $\alpha$ type Fe compound at low cooling rate $(3.6 \mathrm{~K} / \mathrm{s}, 90 \mathrm{~mm})$, as shown in Figs. 5(d), 5(e), $5(\mathrm{~g})$ and 5(i). Increasing the cooling rate to a high level $(17.3 \mathrm{~K} / \mathrm{s}, 20 \mathrm{~mm})$, the $\mathrm{Mn} / \mathrm{Fe}$ ratio also should be less than 0.65 to decrease the ratio of the polyhedral shape $\alpha$ type $\mathrm{Fe}$ compound as much as possible, as shown in Fig. 7(f).

Additionally, most of the Fe compounds appeared as the platelet shape at the low Fe content with high $\mathrm{Mn} / \mathrm{Fe}$ ratio and as the Chinese script shape at high Fe content with high $\mathrm{Mn} / \mathrm{Fe}$ under the high cooling rate, as shown in Figs. 7(c) 

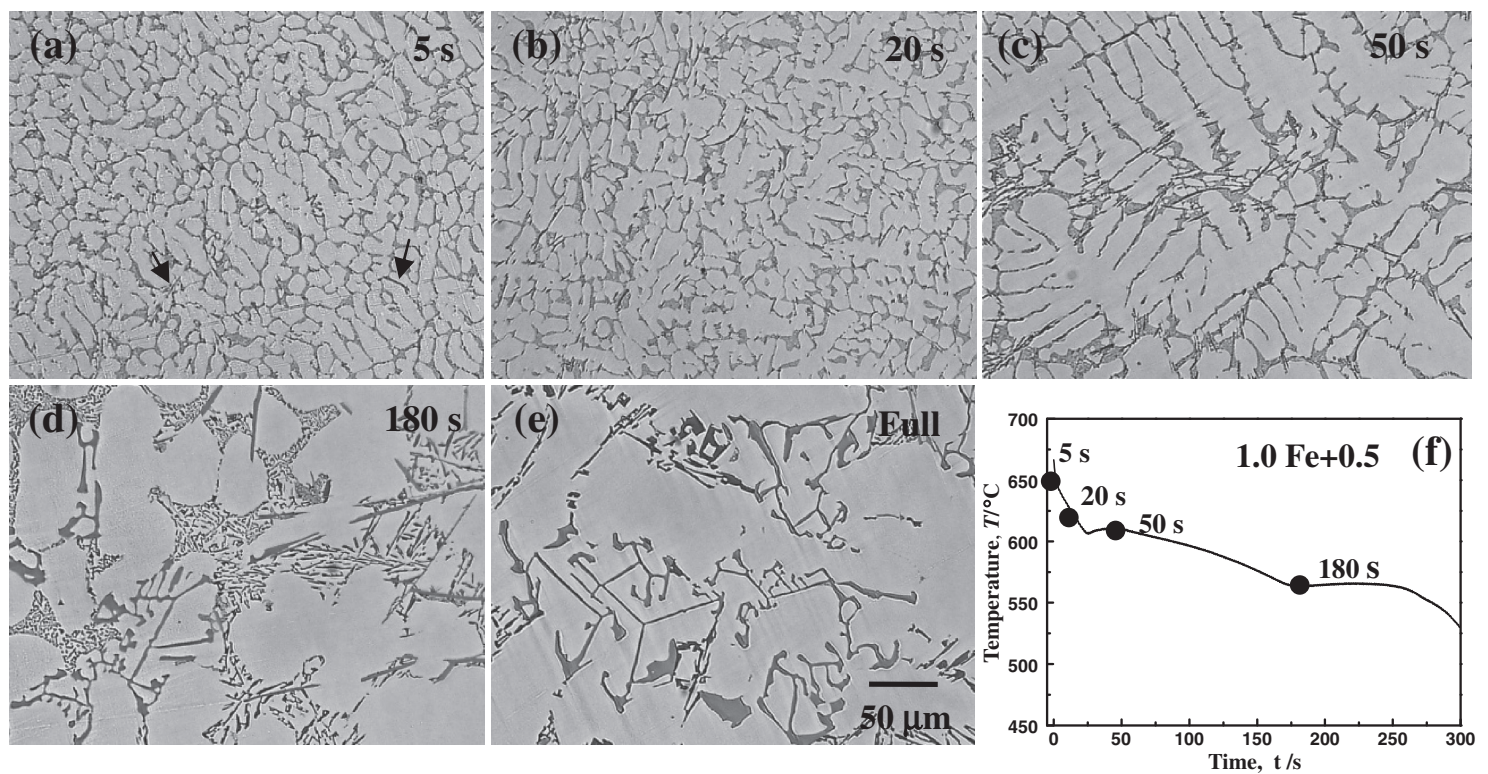

Fig. 8 Microstructures of the alloy $1.0 \mathrm{Fe}+0.5$ water-quenched after different air cooling time: (a) $5 \mathrm{~s}$, (b) $20 \mathrm{~s}$, (c) $50 \mathrm{~s}$, (d) $180 \mathrm{~s}$ and (e) full solidification and its full cooling curve (f).
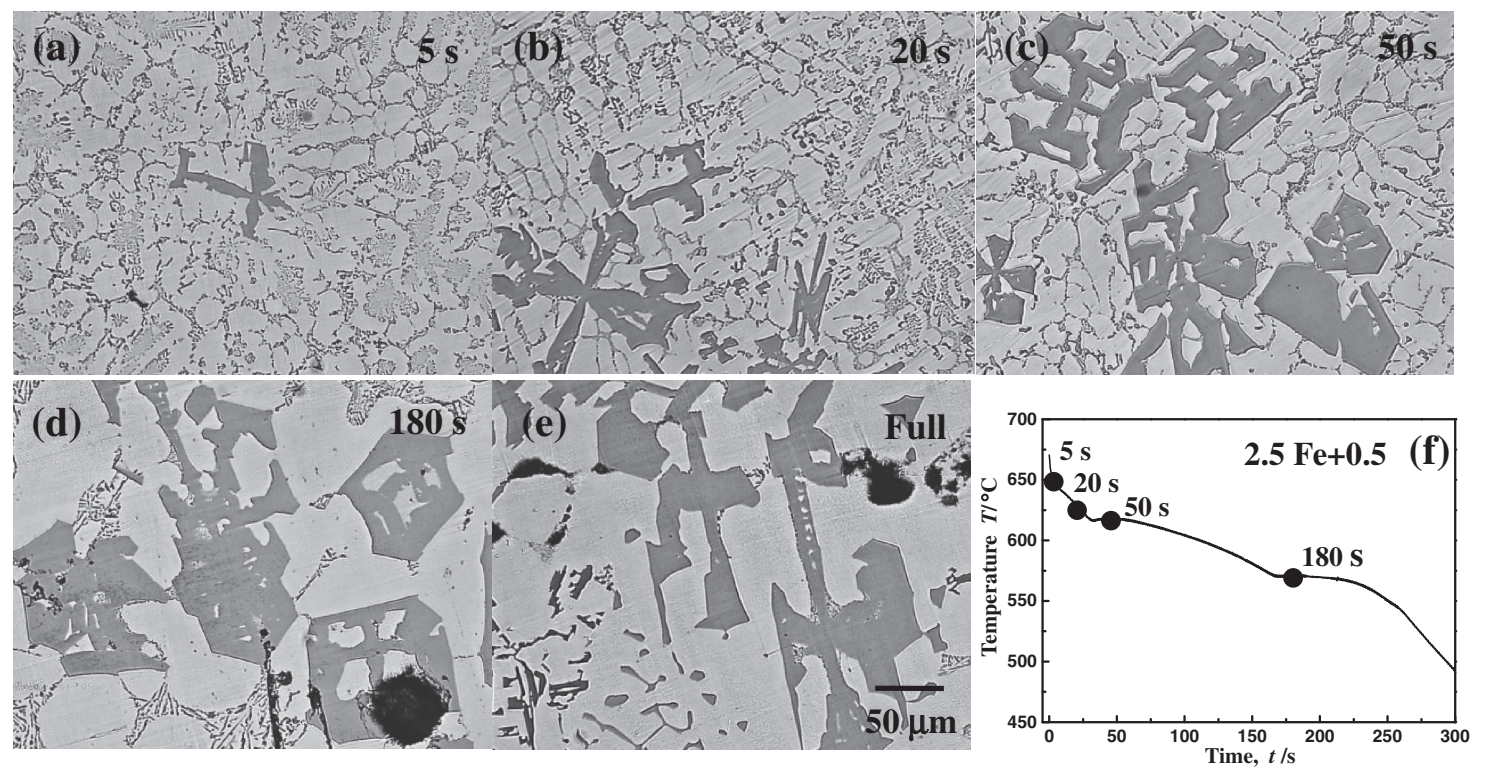

Fig. 9 Microstructures of the alloy $2.5 \mathrm{Fe}+0.5$ water-quenched after different air cooling time: (a) $5 \mathrm{~s}$, (b) $20 \mathrm{~s}$, (c) $50 \mathrm{~s}$, (d) $180 \mathrm{~s}$ and (e) full solidification and its full cooling curve (f).

and 7(f). It is considered that the platelet $\beta$ type Fe compound can solidify earlier than Chinese script $\alpha$ type $\mathrm{Fe}$ compound. The formation of the polyhedral shape $\mathrm{Fe}$ compound mainly came from the growth of the Chinese script Fe compound.

For the further understanding of the solidification sequence of the different $\mathrm{Fe}$ compounds, the water-quenched experiments during air cooling were conducted. The results are shown in Figs. 8 and 9. In the alloy $1.0 \mathrm{Fe}+0.5$, the Fe compounds appeared as the very small size platelet shape at the beginning of the solidification, as shown in Fig. 8(a). With increasing the air cooling time, the size of these small $\mathrm{Fe}$ compounds increased along with the decrease of their number density, as shown in Figs. 8(b) and 8(c). Almost no compound appeared as Chinese script shape even the air cooling time was $50 \mathrm{~s}$. However, when the air cooling time reached to $180 \mathrm{~s}$, most of the Fe compounds showed the Chinese script. Meanwhile, the amount and volume fraction of platelet Fe compound decreased, as shown in Figs. 8(c) and $8(\mathrm{~d})$. This is the direct evidence to prove that the Fe compound crystallized as the platelet $\beta$ type compound at the beginning of the solidification. With the solidification proceeding, the Chinese script $\alpha$ type Fe compound became the dominant one.

In the alloy $2.5 \mathrm{Fe}+0.5$, even at the beginning of the solidification, most of the Fe compounds appeared as the Chinese script shape and some of them appeared as the polyhedral shape, as shown in Fig. 9(a). With increasing the air cooling time, the size and ratio of the polyhedral shape Fe compound particles greatly increased along with the decrease 
of the ratio of the Chinese script Fe compound particles, as shown in Fig. 9(b). Most of the Fe compounds appeared as the polyhedral shape at the air cooling time of $50 \mathrm{~s}, 180 \mathrm{~s}$ and full solidification, as shown in Figs. 9(c)-9(e). It is clearly demonstrated that most of the polyhedral shape Fe compound particles came from the growth of the Chinese script Fe compound particles, not solidified as the primary phase.

\section{Conclusions}

The influence of the Fe content, $\mathrm{Mn} / \mathrm{Fe}$ ratio and cooling rate on the modification process of the $\mathrm{Fe}$ intermetallic compounds in the cast A356 based alloys was investigated. Moreover, the solidification sequence of the Fe compounds was revealed by water-quenched experiments. The obtained results are summarized as follows:

(1) Fe content greatly influences the size of the platelet $\beta$ type Fe compound in the alloys without $\mathrm{Mn}$ addition. The size of the $\beta$ type $\mathrm{Fe}$ compound increases significantly with increasing the Fe content.

(2) The Mn addition was effective to modify the platelet $\beta$ type $\mathrm{Fe}$ compound to more compact compounds, Chinese script and/or polyhedral shape $\alpha$ type Fe compound. The ratio of these different Fe compounds was greatly affected by the $\mathrm{Mn} / \mathrm{Fe}$ ratio and the cooling rate in a given Fe level.

(3) In the alloys with $\mathrm{Mn}$ addition, the $\mathrm{Fe}$ compound crystallized as the platelet $\beta$ type Fe compound at the beginning of the solidification. With the solidification proceeding, the Chinese script $\alpha$ type Fe compound became the dominant one. Additionally, the formation of polyhedral shape $\alpha$ type Fe compound mainly came from the growth of Chinese script $\alpha$ type Fe compound.

\section{Acknowledgments}

The authors acknowledge the financial support from the Japan Foundry Engineering Society and the China Scholarship Council (CSC) for the award of a scholarship to the first author for his study in Japan as a doctoral student.

\section{REFERENCES}

1) N. A. Below, A. A. Aksenov and D. G. Eskin: Iron in Aluminum Alloys, (Taylor \& Francis Inc, New York, 2002) pp. 1-7.

2) L. Wang, D. Apelian and M. M. Makhlouf: AFS Trans. 146 (1999) 231-238.

3) L. Backerud, G. Chai and J. Tamminen: Solidification Characteristics of Aluminium Alloys, Foundry Alloys Vol. 2, (AFS/Skanaluminum, 1990) pp. 71-84.

4) S. Shivkumar, L. Wang and D. Apelian: JOM 43 (1991) 26-32.

5) P. Ashtari, H. Tezuka and T. Sato: Scr. Mater. 51 (2004) 43-46.

6) L. F. Mondolfo: Aluminum Alloys: Structure and Properties, (Butterworths, London, 1976) 661-663.

7) M. V. Kral: Mater. Lett. 59 (2005) 2271-2276.

8) X. J. Cao and J. Campbell: Int. J. Cast Met. Res. 13 (2000) 175-184.

9) X. J. Cao and J. Campbell: Shape Casting: The John Campbell Symposium, ed. by M. Tiryakiogly and P. N. Crepeau, (The Minerals, Metals \& Materials Society, 2005) pp. 255-262.

10) S. Seifeddine and I. L. Svensson: Metall. Sci. Technol. 27 (2009) 1120.

11) P. Ashtari, H. Tezuka and T. Sato: Mater. Trans. 44 (2003) 2611-2616.

12) P. N. Crepeau: AFS Trans. 103 (1995) 361-366.

13) A. Couture: AFS Int. Casting Metals J. 6 (1981) 9-17.

14) S. G. Shabestari: Mater. Sci. Eng. A 383 (2004) 289-298.

15) J. Y. Hwang, H. W. Doty and M. J. Kaufman: Mater. Sci. Eng. A 488 (2008) 496-504.

16) C. M. Dinnis, J. A. Tayor and A. K. Dahle: Metall. Mater. Trans. A 37 (2006) 3283-3291.

17) B. Dutta and M. Rettenmayr: Mater. Sci. Eng. A 283 (2000) 218-224.

18) Y. H. Zhang, Y. C. Liu, Y. J. Han, C. Wei and Z. M. Gao: J. Alloy. Compd. 473 (2009) 442-445. 